\title{
Impact of temperature dependence on the possible contribution of organics to new particle formation in the atmosphere
}

\author{
Fangqun Yu ${ }^{1}$, Gan Luo $^{1}$, Alexey B. Nadykto ${ }^{1,2}$, and Jason Herb ${ }^{1}$ \\ ${ }^{1}$ Atmospheric Sciences Research Center, State University of New York at Albany, 251 Fuller Road, Albany, \\ New York 12203, USA \\ ${ }^{2}$ Department of Applied Mathematics, Moscow State University of Technology "Stankin", Vadkovsky 1, \\ Moscow 127055, Russia \\ Correspondence to: Fangqun Yu (fyu@albany.edu)
}

Received: 12 September 2016 - Discussion started: 19 October 2016

Revised: 1 March 2017 - Accepted: 2 March 2017 - Published: 18 April 2017

\begin{abstract}
Secondary particles formed via new particle formation (NPF) dominate cloud condensation nuclei $(\mathrm{CCN})$ abundance in most parts of the troposphere and are important for aerosol indirect radiative forcing (IRF). Laboratory measurements have shown that certain organic compounds can significantly enhance the binary nucleation of sulfuric acid and $\mathrm{H}_{2} \mathrm{O}$. According to our recent study comparing particle size distributions measured in nine forest areas in North America with those predicted by a global size-resolved aerosol model, current $\mathrm{H}_{2} \mathrm{SO}_{4}$-organics nucleation parameterizations appear to significantly overpredict NPF and particle number concentrations in summer. The lack of temperature dependence in the current $\mathrm{H}_{2} \mathrm{SO}_{4}$-organics nucleation parameterization has been suggested to be a possible reason for the observed overprediction. In this work, $\mathrm{H}_{2} \mathrm{SO}_{4}-$ organics clustering thermodynamics from quantum chemical studies has been employed to develop a scheme to incorporate temperature dependence into $\mathrm{H}_{2} \mathrm{SO}_{4}$-organics nucleation parameterization. We show that temperature has a strong impact on $\mathrm{H}_{2} \mathrm{SO}_{4}$-organics nucleation rates and may reduce the nucleation rate by $\sim 1$ order of magnitude per $10 \mathrm{~K}$ of temperature increase. The particle number concentrations in summer over North America based on the revised scheme is a factor of more than 2 lower, which is in much better agreement with the observations. With the temperaturedependent $\mathrm{H}_{2} \mathrm{SO}_{4}$-organics nucleation parameterization, the summer CCN concentrations in the lower troposphere in the Northern Hemisphere are about 10-30\% lower compared to the temperature-independent parameterization. This study highlights the importance of the temperature effect and its
\end{abstract}

impacts on NPF in the global modeling of aerosol number abundance.

\section{Introduction}

Atmospheric particles, by acting as cloud condensation nuclei $(\mathrm{CCN})$, modify cloud properties and precipitation, thus indirectly affecting the hydrological cycle and the climate. Aerosol indirect radiative forcing (IRF) remains a major uncertainty in assessing climate change (IPCC, 2013). Secondary particles formed via nucleation dominate particle number concentrations in many parts of the troposphere (Spracklen et al., 2008; Pierce and Adams, 2009; Yu and Luo, 2009), and global simulations indicate that nucleation schemes and parameterizations have a strong effect on the aerosol IRF estimations (Wang and Penner, 2009; Kazil et al., 2010; Yu et al., 2012). Different nucleation schemes, with nucleation rates depending on different variables, predict significantly different spatial patterns and seasonal variations in nucleation rates and CCN concentrations (Yu et al., 2010, 2015). Therefore, it is important to understand the mechanisms of new particle formation (NPF) and the key parameters controlling the contribution of NPF to $\mathrm{CCN}$ formation under a wide range of varying atmospheric conditions and to validate their representation in regional and global climate models.

A number of laboratory chamber studies indicate that certain organic species can significantly enhance NPF (e.g., Zhang et al., 2004; Riccobono et al., 2014). This finding may 
have important implications for the interactions of anthropogenic and biogenic emissions and the associated climate forcing. In this regard, it is necessary to assess the ability of organics-enhanced nucleation to explain the nucleation phenomena observed in the atmosphere and to determine the contribution of organics to atmospheric NPF and climate implications. In several laboratory studies, an empirical parameterization of the formation rate as a function of the concentrations of sulfuric acid and low-volatility highly oxidized organics has been derived (Metzger et al., 2010; Riccobono et al., 2014). One of the most important limitations of these empirical parameterizations is that they were derived from the chamber measurements carried out under a limited range of well-controlled conditions, and reliably extrapolating these data to a wide range of atmospheric conditions thus remains a major issue. It should also be noted that empirical activation and kinetic nucleation formulas $\left(J=k_{1}\left[\mathrm{H}_{2} \mathrm{SO}_{4}\right]\right.$ or $J=$ $k_{2}\left[\mathrm{H}_{2} \mathrm{SO}_{4}\right]^{2}$ ) derived from limited field measurements (e.g., Riipinen et al., 2007; Kuang et al., 2008) also do not account for the impact of temperature variations on computed nucleation rates. Although these simple empirical temperatureindependent nucleation parameterizations have been widely used in global aerosol modeling and aerosol IRF studies (e.g., Spracklen et al., 2008; Wang and Penner, 2009; Kazil et al., 2010; Scott et al., 2014; Westervelt et al., 2014; Lupascu et al., 2015), the possible impacts of temperature variations were not considered in these studies.

In a recent study comparing particle size distributions measured in nine forest areas in North America (NA) with those predicted by a global size-resolved (sectional) aerosol model, $\mathrm{Yu}$ et al. (2015) showed that the $\mathrm{H}_{2} \mathrm{SO}_{4}$-organics nucleation parameterization of Riccobono et al. (2014) significantly overpredicts NPF and particle number concentrations in summer (Yu et al., 2015). The lack of temperature dependence in the $\mathrm{H}_{2} \mathrm{SO}_{4}$-organics nucleation parameterization has been suggested as a possible reason for the observed overprediction. The main objectives of the present study are (1) to develop a scheme to incorporate temperature dependence into $\mathrm{H}_{2} \mathrm{SO}_{4}$-organics nucleation parameterization, (2) to assess the ability of the modified parameterization to explain the seasonal variations in NPF in NA, and (3) to study the global implications.

\section{Methods}

\subsection{Organics-mediated nucleation parameterization with temperature dependence (Nucl-OrgT)}

Based on the CLOUD chamber study of nucleation processes involving sulfuric acid and organic compounds of relatively low volatility from the oxidation of pinanediol, Riccobono et al. (2014) derived the following organics-mediated nucleation parameterization (Nucl-Org):
$J_{\text {Nucl-Org }}=k_{m} \times\left[\mathrm{H}_{2} \mathrm{SO}_{4}\right]^{2} \times[\mathrm{BioO} \mathrm{O} O \mathrm{Org}]$,

where $J_{\text {Nucl-Org }}$ is the formation rate $\left(\# \mathrm{~cm}^{-3} \mathrm{~s}^{-1}\right)$ of particles of $\sim 1.7 \mathrm{~nm}, k_{m}$ is the fitting prefactor with a value of $3.27 \times$ $10^{-21} \mathrm{~cm}^{6} \mathrm{~s}^{-1}\left(90 \%\right.$ confidence interval: $1.73 \times 10^{-21}$ to $\left.6.15 \times 10^{-21} \mathrm{~cm}^{6} \mathrm{~s}^{-1}\right)$, and $\left[\mathrm{H}_{2} \mathrm{SO}_{4}\right]$ and [BioOxOrg] are the gas-phase concentrations $\left(\# \mathrm{~cm}^{-3}\right)$ of $\mathrm{H}_{2} \mathrm{SO}_{4}$ and biogenic oxidized organic (BioOxOrg) vapors, respectively. In the chamber study reported in Riccobono et al. (2014), BioOxOrg molecules are organic compounds of relatively low volatility from the oxidation of pinanediol (a first-generation oxidation product of $\alpha$-pinene) and represent later-generation oxidation products of biogenic monoterpenes.

The Nucl-Org parameterization given in Eq. (1), derived from laboratory chamber studies at $T=278 \mathrm{~K}$ and $\mathrm{RH}=39 \%$ (Riccobono et al., 2014), does not consider the possible effect of temperature on the nucleation rate. According to the nucleation theory, nucleation rates are temperature dependent unless the nucleation is barrierless and limited by collision rates only. However, the value of the prefactor $k_{m}$ of $3.27 \times 10^{-21} \mathrm{~cm}^{6} \mathrm{~s}^{-1}$ is well below the three-body collision rate corresponding to the formation of a cluster containing two $\mathrm{H}_{2} \mathrm{SO}_{4}$ molecules and one BioOxOrg molecule. This indicates that the nucleation in the CLOUD chamber under the conditions reported in Riccobono et al. (2014) was not barrierless, and the nucleation rates should thus be temperature dependent.

Based on the classical homogeneous nucleation theory, the rate of nucleation $(J)$ can be generally written in the form

$J=C_{1} \exp (-\Delta G / k T)$,

where $\Delta G$ is the Gibbs free energy needed to form the critical cluster and $C_{1}$ is the prefactor. With $\Delta G=\Delta H-T \Delta S$, where $\Delta H$ and $\Delta S$ are the associated enthalpy and entropy change, we get

$$
\begin{aligned}
J & =C_{1} \exp (-\Delta H / k T+\Delta S / k) \\
& =C_{1} \exp (\Delta S / k) \exp (-\Delta H / k T) \\
& =C_{2} \exp (-\Delta H / k T) .
\end{aligned}
$$

The temperature dependence of the nucleation rate is dominated by the exponential term in Eq. (3), although $C_{2}$ may also weakly depend on temperature. Assuming that $C_{2}$ is independent of temperature and using $J_{\text {Nucl-Org }}$ given in Eq. (1) as the nucleation rate at the reference temperature $T_{0}=278 \mathrm{~K}$, we obtain

$$
\begin{aligned}
& J_{\text {Nucl-OrgT }}=J_{\text {Nucl-Org }} f_{T} \\
& f_{T}=\exp \left[\frac{\Delta H}{k}\left(\frac{1}{T}-\frac{1}{T_{0}}\right)\right],
\end{aligned}
$$

where $f_{T}$ is the correction factor accounting for the temperature dependence. 
Table 1. The changes in enthalpy $(\Delta H)$, entropy $(\Delta S)$, and Gibbs free energy $(\Delta G)$ for the formation of a $\left(\mathrm{C}_{10} \mathrm{H}_{14} \mathrm{O}_{7}\right)\left(\mathrm{H}_{2} \mathrm{SO}_{4}\right)_{2}$ cluster under the standard condition $(P=1 \mathrm{~atm}, T=298 \mathrm{~K})$.

\begin{tabular}{rrrr}
\hline & $\begin{array}{r}\Delta H \\
\left(\mathrm{kcal} \mathrm{mol}^{-1}\right)\end{array}$ & $\begin{array}{r}\Delta S \\
\left(\mathrm{cal} \mathrm{mol}^{-1} \mathrm{~K}^{-1}\right)\end{array}$ & $\begin{array}{r}\Delta G \\
\left(\mathrm{kcal} \mathrm{mol}^{-1}\right)\end{array}$ \\
\hline $\mathrm{C}_{10} \mathrm{H}_{14} \mathrm{O}_{7}+\mathrm{H}_{2} \mathrm{SO}_{4}+\mathrm{H}_{2} \mathrm{SO}_{4} \leftrightarrows\left(\mathrm{C}_{10} \mathrm{H}_{14} \mathrm{O}_{7}\right)\left(\mathrm{H}_{2} \mathrm{SO}_{4}\right)_{2}$ & -38.30 & -75.45 & -15.81 \\
\hline
\end{tabular}

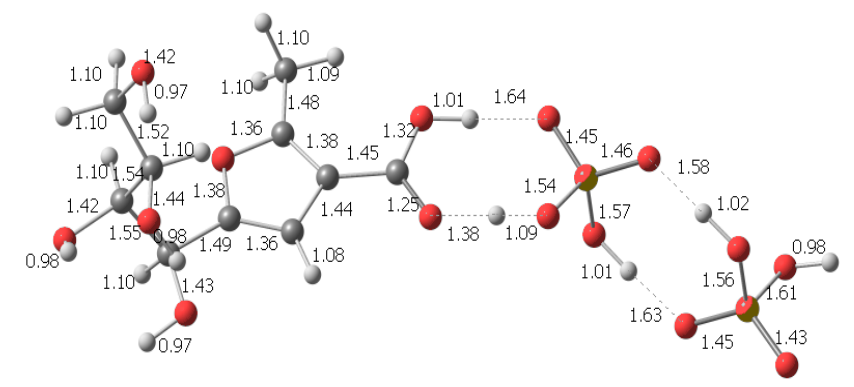

Figure 1. The equilibrium geometry of the most stable isomers of the heteromolecular trimer composed of $\left(\mathrm{C}_{10} \mathrm{H}_{14} \mathrm{O}_{7}\right)\left(\mathrm{H}_{2} \mathrm{SO}_{4}\right)_{2}$ obtained at the PW91PW91/6-311++G(3df,3pd) level of theory. The bonding lengths are in Ångstroms.

One challenge here is to obtain the enthalpy change $(\Delta H)$ associated with the critical cluster formation because it is quite difficult to determine the chemical identities of BioOxOrg molecules involved in atmospheric nucleation (Elm et al., 2014; Riccobono et al., 2014). As a first-order approximation, we use 2-Methyl-5-[(1S,2S,3R)1,2,3,4-tetrahydroxybutyl]-3-furoic acid, a select highly oxidized organic $\mathrm{C}_{10} \mathrm{H}_{14} \mathrm{O}_{7}$ compound, as a proxy for BioOxOrg molecules. The stability of the cluster composed of two $\mathrm{H}_{2} \mathrm{SO}_{4}$ molecules and one $\mathrm{C}_{10} \mathrm{H}_{14} \mathrm{O}_{7}$ molecule has been investigated using the density functional theory (DFT) at the PW91PW91/6-311++G(3df,3pd) level. The PW91PW91 is the most common density functional used in atmospheric studies that predict structure, vibrational spectrums, dipolar properties, and the thermodynamics of atmospheric molecules and molecular clusters with a high degree of confidence. Its predictions, which have been systematically validated against experimental and higher level ab initio Gibbs free energies, are in very good agreement for a number of atmospherically relevant molecules and clusters (e.g., Herb et al., 2013; Elm et al., 2013; Nadykto et al., 2015; DePalma et al., 2015). The computations have been carried out using the Gaussian 09 suite of programs (Frisch et al., 2009).

Figure 1 presents the equilibrium geometry of the most stable isomers of the heteromolecular trimer composed of $\left(\mathrm{C}_{10} \mathrm{H}_{14} \mathrm{O}_{7}\right)\left(\mathrm{H}_{2} \mathrm{SO}_{4}\right)_{2}$, and Table 1 reports the corresponding thermodynamic data associated with the formation of this cluster. The computational methodology, the benchmarks of Gibbs free energy changes, and the Cartesian geometries of global minima and local minima located within $1 \mathrm{kcal} \mathrm{mol}^{-1}$ of the global minima, along with the interac-

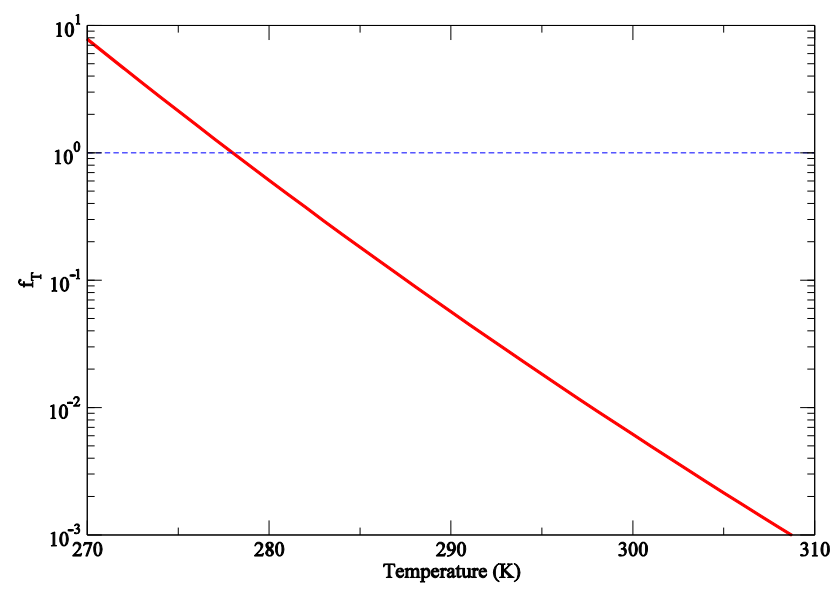

Figure 2. The calculated temperature dependence correction factor for Nucl-Org parameterization $\left(f_{T}\right)$ as a function of $T$.

tions of $\mathrm{C}_{10} \mathrm{H}_{14} \mathrm{O}_{7}$ and $\mathrm{H}_{2} \mathrm{SO}_{4}$ with some base molecules, will be detailed in a separate paper. Here, as a first-order approximation, we use a $\Delta H$ value of $-38.30 \mathrm{kcal} \mathrm{mol}^{-1}$ to calculate the temperature-dependent factor $f_{T}$ in Eq. (5). Figure 2 shows the calculated value of $f_{T}$ as a function of $T$. It is clear from Fig. 2 that $f_{T}$ decreases significantly as $T$ increases, by roughly 1 order of magnitude per $10 \mathrm{~K}$. When $T<269 \mathrm{~K}, f_{T}$ becomes larger than 10 and increases with decreasing $T$. $f_{T}$ is set to have a maximum value so that $J_{\text {Nucl-OrgT }}$ does not exceed the three-body kinetic collision rate for forming a cluster containing two $\mathrm{H}_{2} \mathrm{SO}_{4}$ molecules and one BioOxOrg molecule, which depends on $T$ as well as the mass and sizes of the colliding molecules. At $T=270 \mathrm{~K}$, the maximum value of $f_{T}$ is $\sim 38$. Compared to the original $J_{\text {Nucl-Org }}$ parameterization of Riccobono et al. (2014) (Eq. 1) derived from laboratory chamber studies at $T=278 \mathrm{~K}$ and not taking into account the temperature dependence of nucleation rates (i.e., $f_{T}=1$; the dashed line in Fig. 2), the revised parameterization $J_{\text {Nucl-OrgT }}=f_{T} J_{\text {Nucl-Org }}$ predicts quite a different nucleation rate in the atmosphere, especially in the summer season, when both $T$ and VOC emissions are at peak values.

It should be noted that $f_{T}$ shown in Fig. 2 is subject to large uncertainty because of the potential difference between the molecules involved in the nucleation and the proxy molecule shown in Fig. 1. The thermodynamic data for the formation of $\left(\mathrm{H}_{2} \mathrm{SO}_{4}\right)_{2}(\mathrm{BioOxOrg})$ clusters are quite limited. 

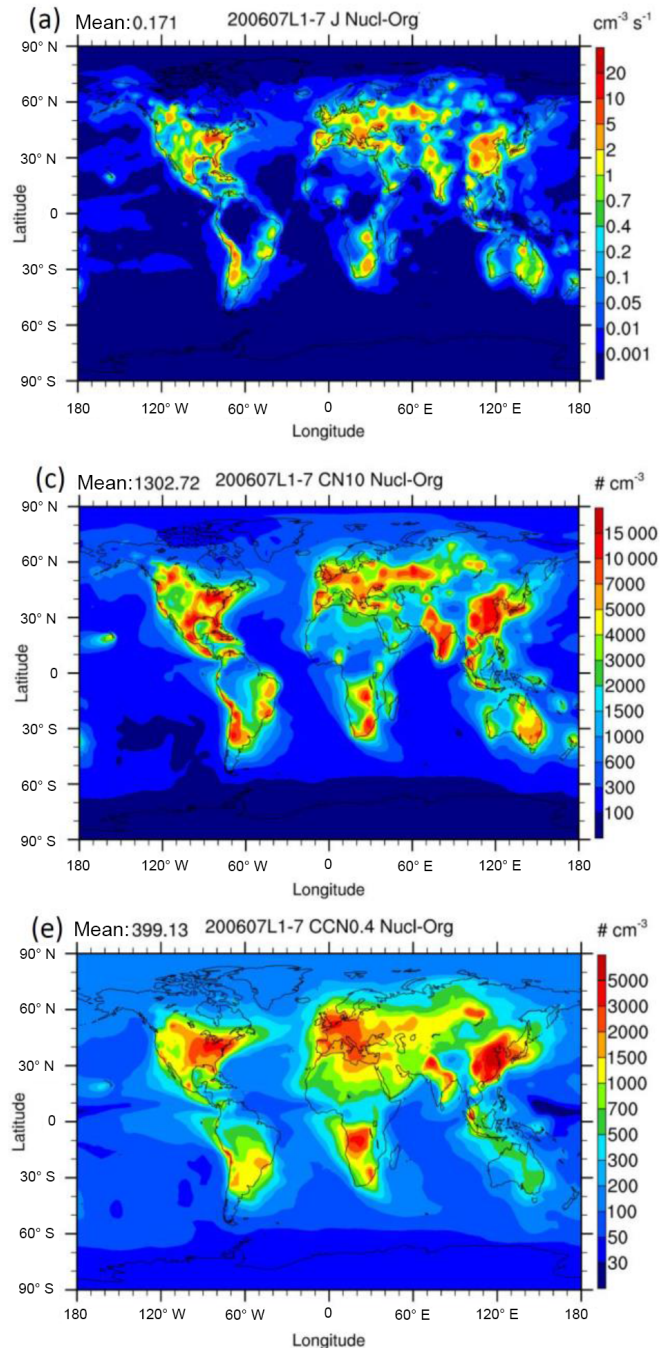
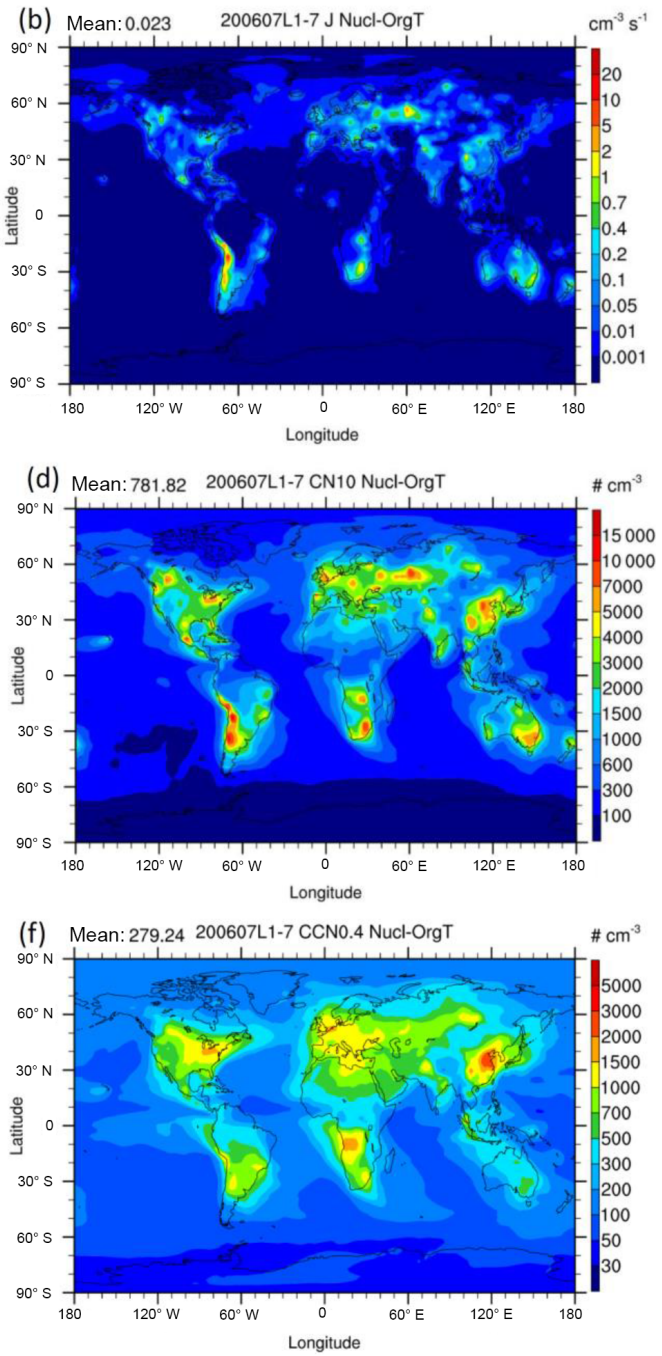

Figure 3. The horizontal distributions of monthly mean nucleation rates $(J)(\mathbf{a}, \mathbf{b})$, the concentrations of condensation nuclei larger than $10 \mathrm{~nm}(\mathrm{CN} 10)(\mathbf{c}, \mathbf{d})$, and the concentrations of cloud condensation nuclei at a water supersaturation ratio of $0.4 \%$ (CCN0.4) (e, f) in the boundary layer $\left(0-1 \mathrm{~km}\right.$ above the surface) in July 2006 based on two organics-mediated nucleation schemes: $J_{\text {Nucl-Org }}$ (left panels) and $J_{\text {Nucl-OrgT }}$ (right panels).

Elm et al. (2014) investigated the molecular interactions between the $\alpha$-pinene oxidation product pinic acid and sulfuric acid using computational methods and reported a $\Delta H$ value of $-42.5 \mathrm{kcal} \mathrm{mol}^{-1}$ for the formation of $\left(\mathrm{H}_{2} \mathrm{SO}_{4}\right)_{2}$ (pinic acid). More negative $\Delta H$ implies a stronger temperature dependence. The sensitivity of $f_{T}$ values to $\Delta H$ can be readily calculated from Eq. (4). For example, a fairly large uncertainty of $5 \mathrm{kcal} \mathrm{mol}^{-1}$ in $\Delta H$ leads to the uncertainty in $f_{T}$ of a factor of $\sim 1.4$ at $T=288 \mathrm{~K}$, while the extremely large $20 \mathrm{kcal} \mathrm{mol}^{-1}$ variation in $\Delta H$ alters $f_{T}$ at $T=288 \mathrm{~K}$ by a factor of $\sim 3.5$. The sensitivity of predicted nucleation rates and particle number concentrations to $\Delta H$ values is presented in Sect. 3. Despite possible uncertainties in $f_{T}$, the temperature-dependent $J_{\text {Nucl-OrgT }}$ is likely to be more real- istic than $J_{\text {Nucl-Org }}$, in which the temperature dependence is neglected.

\subsection{GEOS-Chem model and global simulations}

This work represents a major global modeling attempt in studying the effect of temperature on organics-mediated nucleation in the atmosphere. This study is built upon the work reported in Yu et al. (2015), and we use the same global model (GEOS-Chem) and configurations as those described in Yu et al. (2015). GEOS-Chem is a global 3-D model of atmospheric composition driven by assimilated meteorological observations from the Goddard Earth Observing System (GEOS) of the NASA Global Modeling and Assimilation Office (GMAO) (e.g., Bey et al., 2001). More detailed information about GEOS-Chem and updates can be found at the 
model website (http://geos-chem.org/). The aerosol simulation is based on a size-resolved (sectional) advanced particle microphysics (APM) model incorporated into GESO-Chem by Yu and Luo (2009) and considers the successive oxidation aging of the oxidation products of various VOCs ( $\mathrm{Yu}$, 2011). In GEOS-Chem v8-03-02, on which this study and previous work (Yu et al., 2015) is based, the concentration of highly oxidized, low volatility secondary organic gas from the oxidation products of $\alpha$-pinenes ( $\mathrm{LV}-\mathrm{SOG}_{\alpha \text {-pinene }}$ ) is explicitly simulated and used in Eqs. (1) and (4) to calculate organics-mediated nucleation rates. The horizontal resolution of GEOS-Chem employed in this study is $2^{\circ} \times 2.5^{\circ}$, and there are 47 vertical model layers (with 14 layers from the surface to $\sim 2 \mathrm{~km}$ above the surface). Other relevant model configurations (including emission inventories and various schemes) can be found in Yu et al. (2015).

The main difference between the present study and the previous results reported by Yu et al. (2015) is that the present study employs the $T$-dependent Nucl-Org parameterization given in Eq. (4) instead of the $T$-independent parameterization of Riccobono et al. (2014). In addition, the study of Yu et al. (2015) focuses only on the NA region, while in this work, the discussion on organics-mediated nucleation is expanded to the whole globe.

\section{Results}

Figure 3 shows the effect of the $T$-dependent correction factor on the simulated global distributions of monthly mean (July 2006) nucleation rates, the particle number, and the $\mathrm{CCN}$ concentrations in the boundary layer $(0-1 \mathrm{~km}$ above the surface). The high biogenic VOC emissions in the summer coupled with strong photochemistry lead to higher concentrations of $\mathrm{LV}_{-} \mathrm{SOG}_{\alpha \text {-pinene }}$ or BioOxOrg (Yu et al., 2015); hence, according to the parameterization of Riccobono et al. (2014) (i.e., Eq. 1), there is significant organicsmediated nucleation (Fig. 3a) and higher particle number concentrations (Fig. 3c and e). However, the high temperature in the summer substantially lowers nucleation rates (Fig. 3b) and reduces the global monthly mean nucleation rate in the boundary layer from $0.17 \mathrm{~cm}^{-3} \mathrm{~s}^{-1}$ (Fig. 3a) to $0.02 \mathrm{~cm}^{-3} \mathrm{~s}^{-1}$, with a stronger effect in the Northern Hemisphere (Fig. 3b). As a result, the global monthly means CN10 and CCN0.4 in the boundary layer decrease by 40 and $30 \%$, respectively.

A $\Delta H$ value of $-38.3 \mathrm{kcal} \mathrm{mol}^{-1}$ was used to calculate $J_{\text {Nucl-OrgT }}$ in Fig. $3 b$. The impact of $\Delta H$ values (from 0 to $58.3 \mathrm{kcal} \mathrm{mol}^{-1}$ ) on $J_{\text {Nucl-OrgT }}, \mathrm{CN} 10$, and CCN0.4 averaged in the boundary layer over the whole globe for the same summer month is presented in Fig. 4. A zero value of $\Delta H$ corresponds to the case of no $T$-dependent correction (i.e., $J_{\text {Nucl-Org }}$; Fig. $3 a$ ). $J_{\text {Nucl-OrgT }}, \mathrm{CN} 10$, and CCN0.4 are more sensitive to $\Delta H$ when $\Delta H$ is small $\left(<\sim 30 \mathrm{kcal} \mathrm{mol}^{-1}\right)$, with $J_{\text {Nucl-OrgT }}$ decreasing by a fac-

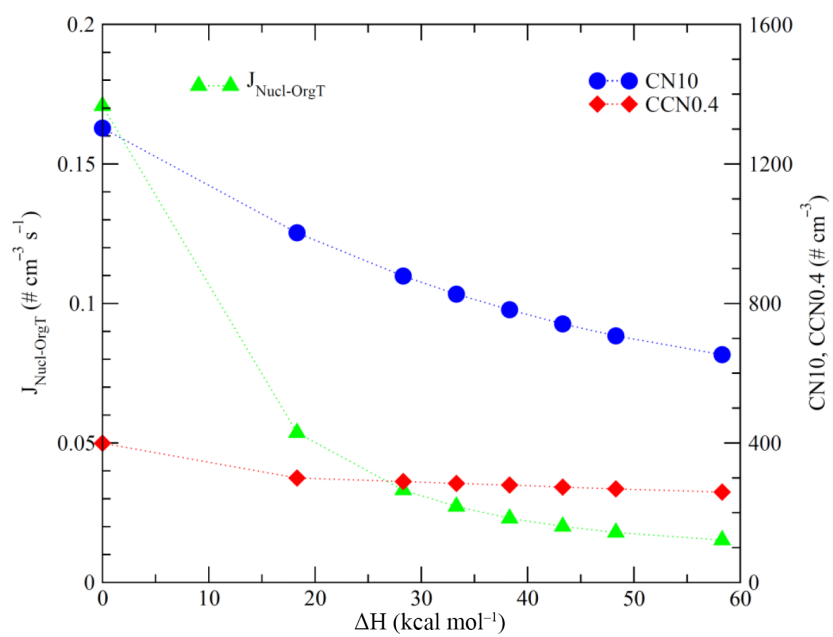

Figure 4. The dependence of organics-mediated nucleation rates (left axis). $\mathrm{CN} 10$ and CCN0.4 (right axis) averaged in the boundary layer $(0-1 \mathrm{~km})$ over the whole globe for July 2006 on the $\Delta H$ values assumed in calculating the temperature dependence correction factor for the Nucl-Org parameterization $\left(f_{T}\right)$.

tor of $5, \mathrm{CN} 10$ by $33 \%$, and CCN0.4 by $28 \%$ as $\Delta H$ increases from 0 to $28.3 \mathrm{kcal} \mathrm{mol}^{-1}$. A further increase in $\Delta H$ from 28.3 to $58.3 \mathrm{kcal} \mathrm{mol}^{-1}$ reduces $J_{\text {Nucl-OrgT }}, \mathrm{CN} 10$, and CCN0.4 by 100,25 , and $10 \%$, respectively. It can be seen from Fig. 4 that the $T$-dependent correction, even with a smaller value of $\Delta H$, is important. On the other hand, the effect of potential uncertainty in $\Delta H$ around the values derived from the quantum calculation $\left(\sim 40 \mathrm{kcal} \mathrm{mol}^{-1}\right.$; see Sect. 2.1) is relatively weaker.

As we have pointed out earlier, the previous comparisons of the simulated and observed particle size distributions measured in nine forest areas in North America (NA) (Yu et al., 2015) showed that $J_{\text {Nucl-Org }}$ parameterization (Eq. 1) overpredicts the condensation nuclei number concentrations in the size range between 10 and $100 \mathrm{~nm}\left(\mathrm{CN}_{10-100}\right)$ at these sites in summer by a factor of around 2 on average (Yu et al., 2015). To examine the extent to which the revised parameterization considering $T$ dependence (Eq. 4) can improve the agreement of the simulations with the measurements, we present the monthly mean horizontal distributions of CN10 zoomed in to the NA region in Fig. 5 and the observed and simulated $\mathrm{CN}_{10-100}$ averaged over the nine forest sites in Fig. 6. It can be clearly seen from Fig. 5 that the simulated monthly mean $\mathrm{CN} 10$ values in the NA boundary layer based on $J_{\text {Nucl-OrgT }}$ (Eq. 4) are about a factor of 2 lower than those based on $J_{\text {Nucl-Org }}$ (Eq. 1), with a larger difference in the lower latitude part of the domain where $T$ is higher. When the effect of $T$ on Nucl-Org is taken into account, the domain-wide average $\mathrm{CN} 10$ value decreases from 4600 to $2200 \mathrm{\#} \mathrm{cm}^{-3}$, and Fig. 6 shows that the simulated $\mathrm{CN}_{10-100}$ averaged over the nine forest sites (with the locations marked in Fig. 5; see Yu et al. (2015) for details) agrees much better 

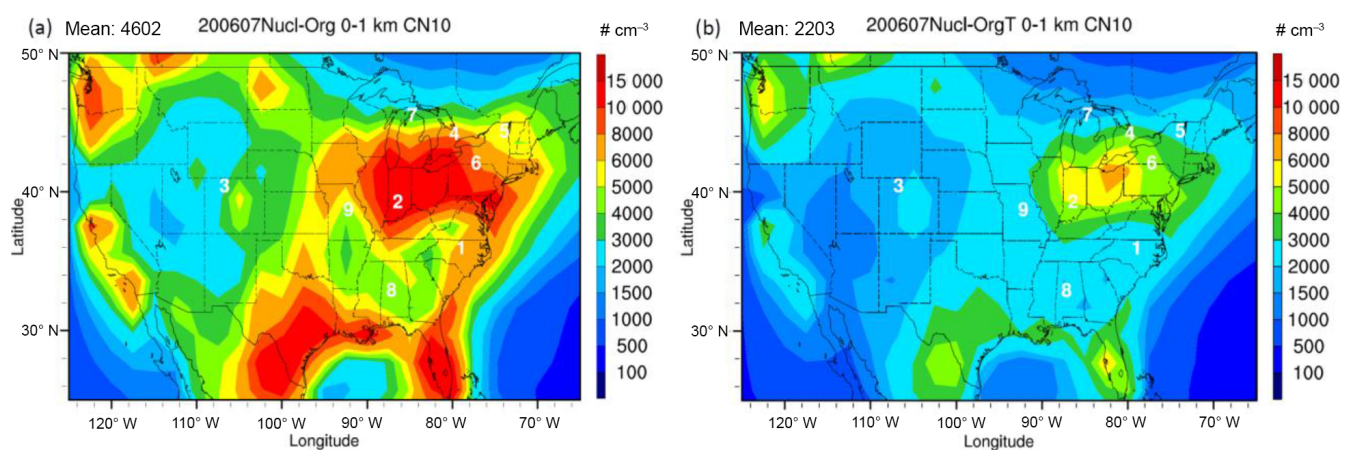

Figure 5. The horizontal distributions of monthly mean CN10 in the boundary layer ( $0-1 \mathrm{~km}$ above surface) in July 2006 based on two organics-mediated nucleation schemes: (a) $J_{\text {Nucl-Org }}$ and (b) $J_{\text {Nucl-OrgT }}$. The locations of nine forest sites where observed particle size distribution measurements have been taken and used for comparison in Yu et al. (2015).

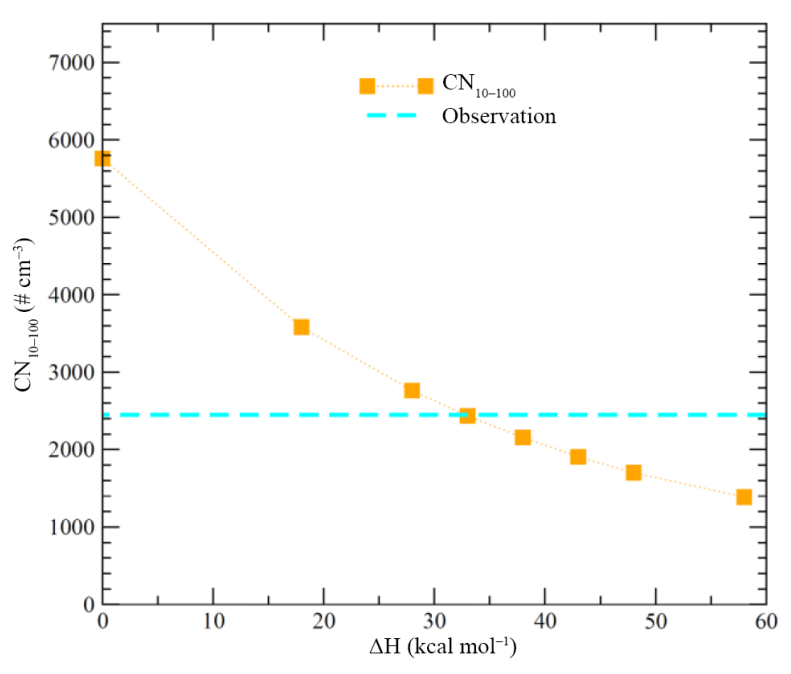

Figure 6. The effect of $\Delta H$ values on simulated number concentrations of condensation nuclei in the size range between 10 and $100 \mathrm{~nm}\left(\mathrm{CN}_{10-100}\right)$ in the boundary layer $(0-1 \mathrm{~km})$ for July 2006 averaged over nine forest sites in North America (NA; locations marked in Fig. 5). The horizontal dashed line shows the average of $\mathrm{CN}_{10-100}$ observed in a summer month at the nine sites.

with that of the observed. It can also be seen from Fig. 6 that $\mathrm{CN}_{10-100}$ over the NA forest sites is more sensitive to $\Delta H$ values than the global mean CN10 shown in Fig. 4; a $\Delta H$ of $\sim 35 \mathrm{kcal} \mathrm{mol}^{-1}$ agrees best with the observations.

To further illustrate the difference and improvement for the cases with and without the $T$-dependent correction, we present in Fig. 7 a set of detailed comparisons of the simulated and observed evolution of particle size distributions during two 10-day periods in March and July 2006 in Duke Forest (Pillai et al., 2013). We also present a time series of $\mathrm{CN}_{10-100}$ (integrated from PSDs), which gives a good overall representation of particle nucleation and growth. The observed PSDs and simulated PSDs based on $J_{\text {Nucl-Org }}$ have been discussed in Yu et al. (2015) and are repeated here for comparison with the $J_{\text {Nucl-OrgT }}$ scheme in order to demon- strate the impact of temperature on nucleation and particle number concentrations. Although the present work focuses on the summer months, when the largest difference between the $J_{\text {Nucl-Org }}$ prediction and observation is seen, we also show in Fig. 7 the simulations for a 10-day period in March for the purposes of comparison. The NPF events observed in Duke Forest are much more frequent, and the concentrations of nucleation mode particles are much higher in the spring than in the summer (Fig. 7a and b). The temperature correction (Eq. 4), has a small effect in the spring (Fig. 7c, e, and g) but significantly reduces the nucleation rate and particle number concentration in summer (Fig. $7 \mathrm{~d}$, e, and f). The $J_{\text {Nucl-Org }}$ scheme (Eq. 1) predicts strong nucleation events (Fig. 7d) and significant diurnal variations in $\mathrm{CN}_{10-100}$ (Fig. 7h) almost every day in the summer period, which clearly contradicts the observations (Fig. 7b). The high nucleation rates in the summer based on the $J_{\text {Nucl-Org }}$ scheme can be easily explained by the much higher BioOxOrg concentrations as a result of high VOC emissions and stronger photochemistry. Nevertheless, the high $T$ in the summer inhibits nucleation (Eq. 4), and the temperature correction factor substantially improves the agreement of the simulated evolution of PSDs (Fig. 7b, d, f) and $\mathrm{CN}_{10-100}$ (Fig. 7h) with the observations.

Figure 8 shows the ratios of the $\mathrm{CCN}$ concentration in the lower troposphere $(0-3 \mathrm{~km})$ based on Nucl-Org to the $\mathrm{CCN}$ concentration based on Nucl-OrgT. The CCN concentrations are calculated at a water supersaturation ratio of $0.2 \%$ (CCN0.2) from the simulated PSDs. As a result of higher nucleation rates, CCN0.2 based on Nucl-Org are about 10-20\% higher than those based on Nucl-OrgT in July over most parts of the Northern Hemisphere (Fig. 6a), with the largest difference up to 30-70\% reached over parts of NA, Europe, and Asia. It is noteworthy that the present model simulation only considers the Nucl-Org parameterization. While this enables us to show the effect of the $T$-dependent correction more unambiguously, it may overestimate the sensitivity of CCN to changes in the nucleation rate as a result of atmospheric saturation when all nucleation mechanisms (including nonor- 

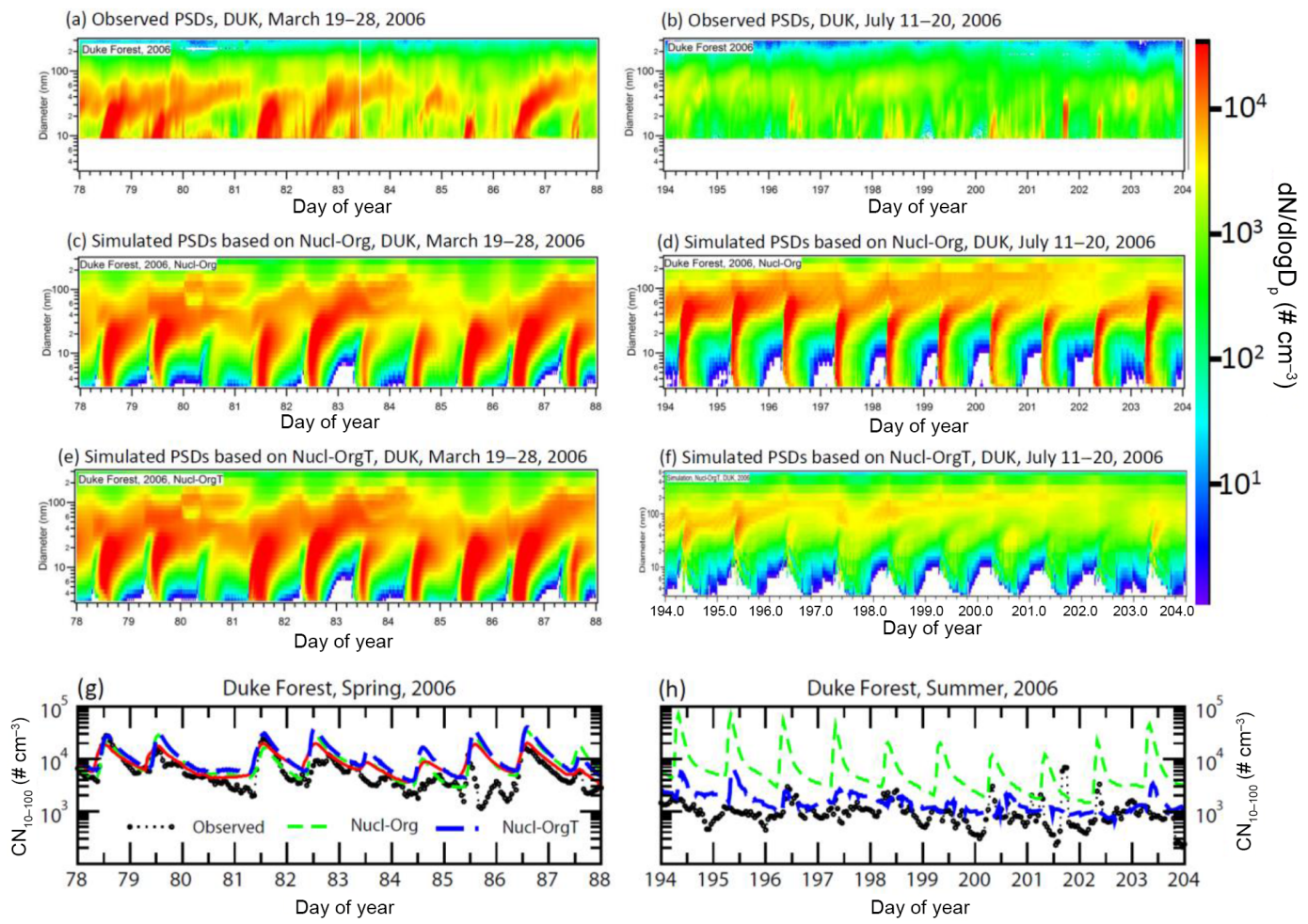

Figure 7. The particle size distributions (PSDs) observed $(\mathbf{a}, \mathbf{b})$ and simulated based on the Nucl-Org (c, d) and Nucl-OrgT (e, f) schemes during two 10-day periods in March (a, c, e) and July (b, d, f) 2006 in Duke Forest (DUK), along with a time series of the concentration of condensation nuclei between 10 and $100 \mathrm{~nm}\left(\mathrm{CN}_{10-100}\right)(\mathbf{g}, \mathbf{h})$.

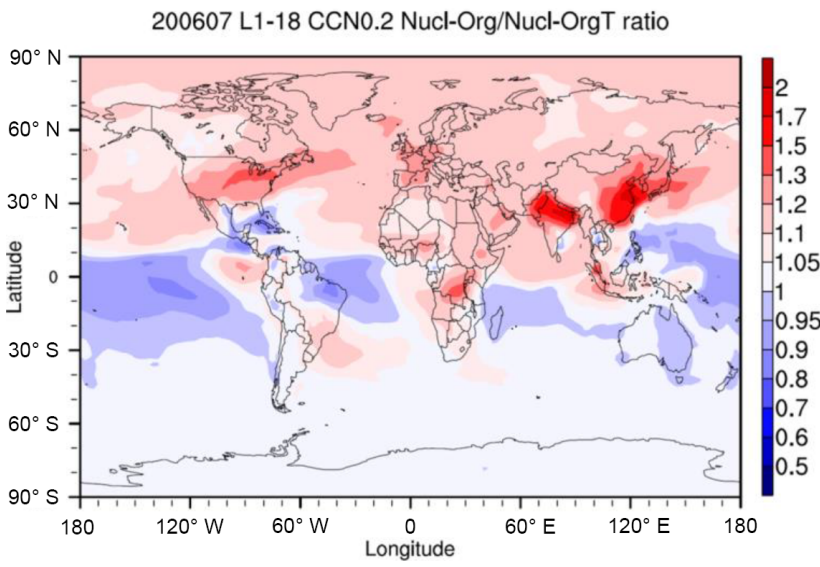

Figure 8. The ratios of the concentration of $\mathrm{CCN}$ (at a water supersaturation ratio of $0.2 \%)$ in the lower troposphere $(0-3 \mathrm{~km})$ based on the Nucl-Org scheme to those based on the Nucl-OrgT scheme.

ganic nucleation) are present. A further simulation including all individually verified nucleation mechanisms is needed to evaluate the sensitivity of global CCN to the uncertainties associated with various nucleation parameterizations.

\section{Summary and discussion}

Simple empirical nucleation parameterizations, which were derived from laboratory or field measurements under limited conditions and do not consider any temperature dependence of nucleation rates, have been widely used in global aerosol modeling and aerosol indirect radiative forcing studies. Based on the classical nucleation theory, temperature should be one of the key parameters controlling nucleation rates, unless the nucleation is barrierless. A recent study indicates (Yu et al., 2015) that the empirical parameterization of $\mathrm{H}_{2} \mathrm{SO}_{4}$-organics nucleation in Riccobono et al. (2014) significantly overpredicts NPF and particle number concentrations in North America in summer. The lack of temperature dependence in the parameterization has been suggested as a likely reason for the observed overprediction. In the present study, $\mathrm{H}_{2} \mathrm{SO}_{4}$-organics clustering thermodynamics from quantum chemical studies has been employed to develop a scheme for incorporating the temperature dependence into $\mathrm{H}_{2} \mathrm{SO}_{4}$-organics nucleation parameterization, which reduces the global mean nucleation rate in the boundary layer in a summer month by a factor of $\sim 8$ and improves the agreement of the predicted particle number concentrations over North America with the observations. With a temperature-dependent $\mathrm{H}_{2} \mathrm{SO}_{4}$-organics nucleation parameterization, the summer $\mathrm{CCN}$ concentrations in the lower 
troposphere in the Northern Hemisphere are about 10-30\% lower. In view of the potential effects of changes in $\mathrm{CCN}$ concentrations on precipitation (second indirect impact) and cloud cover, it is important to reduce the uncertainties in the NPF calculation in regional and global climate models.

The study highlights the importance of including the temperature dependence of nucleation rates in the global modeling of NPF and aerosol indirect radiative forcing. In a recent study, Dune et al. (2016) also showed a substantial impact of the temperature dependence on the contribution of organic nucleation to overall nucleation. The temperature dependence factor derived in this study can be applied to study the temperature effect on organics-mediated nucleation in the global atmosphere and improve the agreement of the simulated particle number concentrations with the observations. Although it may be subject to uncertainties due to the possible difference between the molecules involved in the nucleation and the proxy molecule, the temperature-dependent $J_{\text {Nucl-OrgT }}$ is likely more realistic than $J_{\text {Nucl-Org }}$, in which the temperature dependence is neglected. Further laboratory measurements and theoretical studies are needed to better understand the effect of temperature on organics-mediated nucleation in the atmosphere.

Data availability. The work described in this paper is based on GEOS-Chem version 8-03-02. The code, written in FORTRAN-90, is portable and efficient on available parallel computing platforms (http://geos-chem.org/). The figures presented in this paper were generated using NCAR Command Language (NCL).

Competing interests. The authors declare that they have no conflict of interest.

Acknowledgements. This study was supported by NASA under grant NNX13AK20G and the NSF under grant 1550816. We would like to acknowledge high-performance computing support from Yellowstone (ark:/85065/d7wd3xhc) provided by NCAR's Computational and Information Systems Laboratory, sponsored by the NSF. The GEOS-Chem model is managed by the Atmospheric Chemistry Modeling Group at Harvard University with support from NASA's Atmospheric Chemistry Modeling and Analysis Program.

Edited by: V.-M. Kerminen

Reviewed by: three anonymous referees

\section{References}

Bey, I., Jacob, D. J., Yantosca, R. M., Logan, J. A., Field, B., Fiore, A. M., Li, Q., Liu, H., Mickley, L. J., and Schultz, M.: Global modeling of tropospheric chemistry with assimilated meteorology: Model description and evaluation, J. Geophys. Res., 106, 23073-23096, 2001.
DePalma, J. W., Wang, J., Wexler, A. S., and Johnston, M. V.: Growth of ammonium bisulfate clusters by adsorption of oxygenated organic molecules, J. Phys. Chem. A, 119, 1119111198, doi:10.1021/acs.jpca.5b07744, 2015.

Dunne, E. M., Gordon, H., Kürten, A., Almeida, J., Duplissy, J., Williamson, C., Ortega, I. K., Pringle, K. J., Adamov, A., Baltensperger, U., and Barmet, P.: Global atmospheric particle formation from CERN CLOUD measurements, Science, 354, 6316, doi:10.1126/science.aaf2649, 2016.

Elm, J., Bilde, M., and Mikkelsen, K. V.: Assessment of binding energies of atmospherically relevant clusters, Phys. Chem. Chem. Phys., 15, 16442-16445, 2013.

Elm, J., Kurten, T., Bilde, M., and Mikkelsen, K. V.: Molecular interaction of pinic acid with sulfuric acid: Exploring the thermodynamic landscape of cluster growth, J. Phys. Chem. A, 118, 7892-7900, 2014.

Frisch, M. J., Trucks, G. W., Schlegel, H. B., Scuseria, G. E., Robb, M. A., Cheeseman, J. R., Scalmani, G., Barone, V., Mennucci, B., Petersson, G. A., and Nakatsuji, H.: Gaussian 09, Gaussian, Inc., Wallingford CT, 2009.

Herb, J., Xu, Y., Yu, F., and Nadykto, A. B.: Large hydrogenbonded pre-nucleation $\left(\mathrm{HSO}_{4}^{-}\right) \quad\left(\mathrm{H}_{2} \mathrm{SO}_{4}\right)_{m}\left(\mathrm{H}_{2} \mathrm{O}\right)_{k}$ and $\left(\mathrm{HSO}_{4}\right)\left(\mathrm{NH}_{3}\right)\left(\mathrm{H}_{2} \mathrm{SO}_{4}\right)_{m}\left(\mathrm{H}_{2} \mathrm{O}\right)_{k}$ Clusters in the Earth's Atmosphere, J. Phys. Chem. A, 117, 133-152, 2013.

IPCC: Climate Change 2013: The Physical Scientific Basis, edited by: Stocker, T. F., Qin, D., Plattner, G. K., Tignor, M., Allen, S. K., Boschung, J., Nauels, A., Xia, Y., Bex, B., and Midgley, B. M., Cambridge Univ. Press, New York, USA, 2013.

Kazil, J., Stier, P., Zhang, K., Quaas, J., Kinne, S., O’Donnell, D., Rast, S., Esch, M., Ferrachat, S., Lohmann, U., and Feichter, J.: Aerosol nucleation and its role for clouds and Earth's radiative forcing in the aerosol-climate model ECHAM5-HAM, Atmos. Chem. Phys., 10, 10733-10752, doi:10.5194/acp-1010733-2010, 2010.

Kuang, C., McMurry, P. H., McCormick, A. V., and Eisele, F. L.: Dependence of nucleation rates on sulfuric acid vapor concentration in diverse atmospheric locations, J. Geophys. Res., 113, D10209, doi:10.1029/2007JD009253, 2008.

Lupascu, A., Easter, R., Zaveri, R., Shrivastava, M., Pekour, M., Tomlinson, J., Yang, Q., Matsui, H., Hodzic, A., Zhang, Q., and Fast, J. D.: Modeling particle nucleation and growth over northern California during the 2010 CARES campaign, Atmos. Chem. Phys., 15, 12283-12313, doi:10.5194/acp-15-12283-2015, 2015.

Metzger, A., Verheggen, B., Dommen, J., Duplissy, J., Prevot, A. S., Weingartner, E., Riipinen, I., Kulmala, M., Spracklen, D. V., Carslaw, K. S., and Baltensperger, U.: Evidence for the role of organics in aerosol particle formation under atmospheric conditions, P. Natl. Acad. Sci. USA, 107, 6646-6651, 2010.

Nadykto, A. B., Herb, J., Yu, F., and Xu, Y.: Enhancement in the production of nucleating clusters due to dimethylamine and large uncertainties in the thermochemistry of amine-enhanced nucleation, Chem. Phys. Lett., 609, 42-49, 2015.

Pierce, J. R. and Adams, P. J.: Uncertainty in global CCN concentrations from uncertain aerosol nucleation and primary emission rates, Atmos. Chem. Phys., 9, 1339-1356, doi:10.5194/acp-91339-2009, 2009.

Pillai, P., Khlystov, A., Walker, J., and Aneja, V. Observation and analysis of particle nucleation at a forest site in southeastern US, Atmosphere, 4, 72-93, 2013. 
Riccobono, F., Schoberberger, S., Scott, C. E., Dommen, J., Ortega, I. K., Rondo, L., Almeida, J., Amorim, A., Bianchi, F., Breitenlechner, M., David, A., Downard, A., Dunne, E. M., Duplissy, J., Ehrhardt, S., Flagan, R. C., Franchin, A., Hansel, A., Juuninen, H., Kajos, M., Keskinen, H., Kupc, A., Kürten, A., Kvashin, A. N., Laaksonen, A., Lehtipalo, K., Makkmutov, V., Mathot, S., Nieminen, T., Onnela, A., Petäjä, T.,Praplan, A. P., Santos, F. D., Schallhart, S., Seinfeld, J. H., Sipilä, M., Spracklen, D. V., Stozhkov, Y., Stratmann, F., Tomé, A., Tsagkogeorgas, G., Vaattlovaara, P., Viisanen, Y., Vrtala, A., Wagner, P. E., Weingartner, E., Wex, H., Wimmer, D., Carslaw, K. S., Curtius, J., Donahue, N. M., Kirkby, J., Kulmala, M., Worsnop, D. R., and Baltensperger, U.: Oxidation products of biogenic emissions contribute to nucleation of atmospheric particles, Science, 344, 717 721,2014

Riipinen, I., Sihto, S.-L., Kulmala, M., Arnold, F., Dal Maso, M., Birmili, W., Saarnio, K., Teinilä, K., Kerminen, V.-M., Laaksonen, A., and Lehtinen, K. E. J.: Connections between atmospheric sulphuric acid and new particle formation during QUEST III-IV campaigns in Heidelberg and Hyytiälä, Atmos. Chem. Phys., 7, 1899-1914, doi:10.5194/acp-7-1899-2007, 2007.

Scott, C. E., Rap, A., Spracklen, D. V., Forster, P. M., Carslaw, K. S., Mann, G. W., Pringle, K. J., Kivekäs, N., Kulmala, M., Lihavainen, H., and Tunved, P.: The direct and indirect radiative effects of biogenic secondary organic aerosol, Atmos. Chem. Phys., 14, 447-470, doi:10.5194/acp-14-447-2014, 2014.

Spracklen, D. V., Carslaw, K. S., Kulmala, M., Kerminen, V.M., Sihto, Riipinen, I., Merikanto, J., Mann, G. W., Chipperfield, M. P., Wiedensohler, A., Birmili, W., and Lihavainen, H.: Contribution of particle formation to global cloud condensation nuclei concentrations, Geophys. Res. Lett., 35, L06808, doi:10.1029/2007GL033038, 2008.

Wang, M. and Penner, J. E.: Aerosol indirect forcing in a global model with particle nucleation, Atmos. Chem. Phys., 9, 239-260, doi:10.5194/acp-9-239-2009, 2009.
Westervelt, D. M., Pierce, J. R., and Adams, P. J.: Analysis of feedbacks between nucleation rate, survival probability and cloud condensation nuclei formation, Atmos. Chem. Phys., 14, 5577 5597, doi:10.5194/acp-14-5577-2014, 2014.

Yu, F.: A secondary organic aerosol formation model considering successive oxidation aging and kinetic condensation of organic compounds: global scale implications, Atmos. Chem. Phys., 11, 1083-1099, doi:10.5194/acp-11-1083-2011, 2011.

Yu, F. and Luo, G.: Simulation of particle size distribution with a global aerosol model: contribution of nucleation to aerosol and CCN number concentrations, Atmos. Chem. Phys., 9, 76917710, doi:10.5194/acp-9-7691-2009, 2009.

Yu, F., Luo, G., Bates, T., Anderson, B., Clarke, A., Kapustin, V., Yantosca, R., Wang, Y., and Wu, S.: Spatial distributions of particle number concentrations in the global troposphere: Simulations, observations, and implications for nucleation mechanisms, J. Geophys. Res., 115, D17205, doi:10.1029/2009JD013473, 2010.

Yu, F., Luo, G., Liu, X., Easter, R. C., Ma, X., and Ghan, S. J.: Indirect radiative forcing by ion-mediated nucleation of aerosol, Atmos. Chem. Phys., 12, 11451-11463, doi:10.5194/acp-1211451-2012, 2012.

Yu, F., Luo, G., Pryor, S. C., Pillai, P. R., Lee, S. H., Ortega, J., Schwab, J. J., Hallar, A. G., Leaitch, W. R., Aneja, V. P., Smith, J. N., Walker, J. T., Hogrefe, O., and Demerjian, K. L.: Spring and summer contrast in new particle formation over nine forest areas in North America, Atmos. Chem. Phys., 15, 13993-14003, doi:10.5194/acp-15-13993-2015, 2015.

Zhang, R., Suh, I., Zhao, J., Zhang, D., Fortner, E. C., Tie, X., Molina, L. T., and Molina, M. J.: Atmospheric new particle formation enhanced by organic acids, Science, 304, 1487-1490, 2004. 